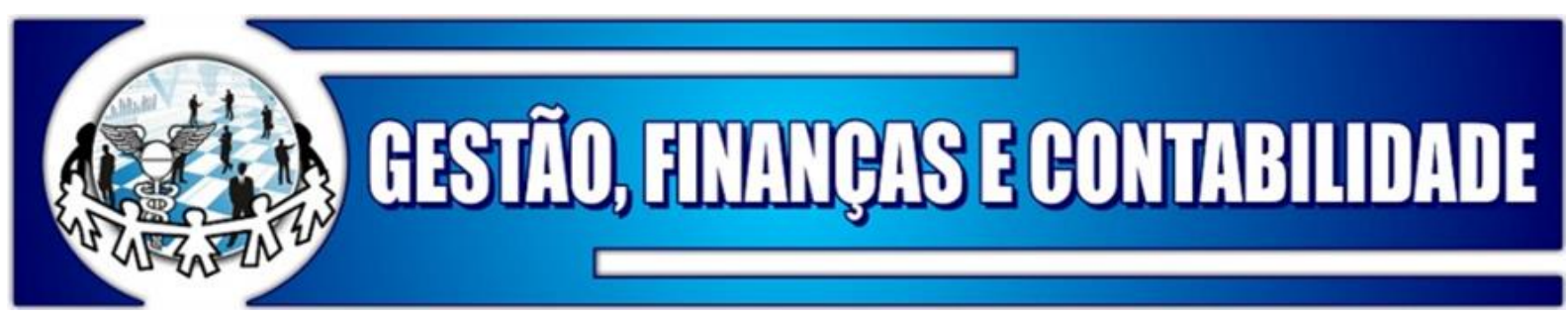

\title{
PANORAMA DA LITERATURA SOBRE A GOVERNANÇA CORPORATIVA: UMA ANÁLISE BIBLIOMÉTRICA DAS BASES TEÓRICAS E ABORDAGENS MAIS UTILIZADAS EM ARTIGOS
}

\section{OVERVIEW OF THE LITERATURE ON CORPORATE GOVERNANCE: A BIBLIOMETRIC ANALYSIS OF THE THEORETICAL BASES AND APPROACHES MOST USED IN ARTICLES}

\section{PANORAMA GENERAL DE LA LITERATURA SOBRE GOBIERNO CORPORATIVO: UN ANÁLISIS BIBLIOMÉTRICO DE BASES TEÓRICAS Y ENFOQUES MÁS USADOS EN ARTÍCULOS}

\author{
João José Ferreira Simões \\ https://orcid.org/0000-0002-0095-0458 \\ Doutorando em Administração no CEPEAD - Centro de Pós-Graduação e \\ Pesquisas em Administração (FACE/UFMG) \\ E-mail: simoes.joao@yahoo.com.br
}

\begin{abstract}
Antônio Artur de Souza
Link do Orcid: https://orcid.org/0000-0002-4725-0758

Professor Titular do Departamento de Ciências Administrativas no CEPEAD (FACE/UFMG) Doutor em Administração pela Universidade de Lancaster, Inglaterra

E-mail: $\underline{\text { artur@face.ufmg.br }}$
\end{abstract}

\section{RESUMO}

Nesta pesquisa foram investigados as bases teóricas e os artigos mais citados nos estudos sobre a governança corporativa por meio de mapeamento bibliométrico utilizando o software VOSviewer. A amostra, composta por 2.965 artigos, foi obtida por meio da base Web of Science. O período de análise, de 2000 a 2018, foi subdivido em três subperíodos devido a ocorrência de eventos financeiros nos Estados Unidos, tendo sido evidenciada a necessidade de melhorias nas práticas de governança corporativa. Acredita-se que o aprimoramento das práticas de governança corporativa sejam o fruto do surgimento de novas propostas apresentadas na literatura investigada, caracterizando a relevância desta pesquisa. Este estudo contribui para a literatura em Finanças ao apresentar as fundações das pesquisas sobre a governança corporativa por meio de mapeamento bibliométrico, podendo auxiliar as futuras pesquisas ao delinear as bases teóricas utilizadas após os eventos de estresse financeiro relatados. As evidências sugerem a predominância da Teoria da Agência nos períodos analisados. Entretanto, também foram observadas a Teoria da Estrutura de Propriedade, Stakeholder Theory, Stewardship Theory e Resource Dependency Theory que poderiam estar associadas aos eventos ocorridos.

Palavras-Chave: VOSviewer; Governança Corporativa; mapeamento bibliométrico; Finanças. 


\begin{abstract}
In this research, the theoretical bases and the articles most cited in studies on corporate governance were investigated through bibliometric mapping using the software VOSviewer. The sample made up of 2,965 articles was obtained through Web of Science database. The analysis period from 2000 to 2018 , was subdivided into three subperiods due to the occurrence of financial events in the United States, and the need for improvements in corporate governance practices was evidenced. It is believed that the improvement of corporate governance practices is the result of the emergence of new proposals presented in the investigated literature, characterizing the relevance of this research. This study contributes to the literature in Finance by presenting the foundations of research on corporate governance through bibliometric mapping and can assist future research by outlining the theoretical bases used after the reported financial stress events. The evidence suggests the predominance of the Agency Theory in the analyzed periods. However, the Property Structure Theory, Stakeholder Theory, Stewardship Theory and Resource Dependency Theory were also observed, which could be associated with the financial events that occurred.
\end{abstract}

Keywords: VOSviewer; Corporate Governance; bibliometric mapping; Finance.

\title{
RESUMEN
}

Se investigaron las bases teóricas y los artículos más citados en estudios sobre gobierno corporativo mediante mapeo bibliométrico utilizando el software VOSviewer. La muestra compuesta por 2.965 artículos se obtuvo en la base de datos Web of Science. El período de análisis de 2000 a 2018, se subdividió en tres subperíodos debido a la ocurrencia de eventos financieros en Estados Unidos, y se evidenció la necesidad de mejoras en las prácticas de gobierno corporativo. Se cree que la mejora de las prácticas de gobierno corporativo es el resultado del surgimiento de nuevas propuestas presentadas en la literatura investigada, caracterizando la relevancia de esta investigación. Este estudio contribuye a la literatura en Finanzas al presentar los fundamentos de la investigación sobre gobierno corporativo a través del mapeo bibliométrico, y puede ayudar a futuras investigaciones al delinear las bases teóricas utilizadas después de los eventos de estrés financiero reportados. La evidencia sugiere el predominio de la Teoría de la Agencia en los períodos analizados. Sin embargo, también se observaron la Teoría de la Estructura de la Propiedad, la Teoría de las Partes Interesadas, la Teoría de la Administración y la Teoría de la Dependencia de los Recursos, que podrían estar asociadas con los eventos financieros que ocurrieron.

Palabras clave: VOSviewer; Gobierno corporativo; mapeo bibliometríco; Finanzas.

\section{INTRODUÇÃO}

No mercado empresarial, mais especificamente aquele de empresas com ações listadas em bolsa de valores, a transparência do processo de gestão tem sido reconhecida como fortemente relacionada ao desempenho das empresas e à segurança do investimento dos acionistas. A governança corporativa, conforme Hart (1995), é um mecanismo que assegura a eficácia da tomada de decisões que não foram previstas no contrato inicial, possibilitando o aumento da riqueza dos acionistas por meio de maior transparência das informações ao estimular e monitorar as decisões do gestor. Entretanto, cenários adversos, podem afetar a continuidade das empresas, colocando em risco o capital de acionistas e credores.

Nos Estados Unidos, a supervalorização dos ativos de empresas de tecnologia culminou, no ano 2000, no estouro da bolha das empresas pontocom, acarretando prejuízo a diversos investidores. Em seguida, ocorreram os escândalos financeiros das empresas Enron (2001), Worldcom (2002), Tyco (2002) e HealthSouth (2003) ao se tornarem públicas as fraudes contábeis cometidas que, conforme Rossoni (2009), indicou mudanças necessárias às práticas 
de governança corporativa. Após alguns anos, os mercados financeiros de todo o mundo foram abalados com a Grande Crise Financeira de 2007-2008, ocorrida nos Estados Unidos, onde foram aplicadas medidas não convencionais de política monetária para evitar o colapso da economia americana. Maranho, da Fonseca e Frega (2016) afirmam que falhas graves nas práticas de governança corporativa colaboraram para a gravidade desta crise. Porém, com o início da normalização da política monetária americana em um período marcado por alta liquidez (Bank for International Settlements, 2017) foi criado um cenário de estresse em alguns mercados pois as empresas deveriam se adaptar à nova realidade de disponibilidade de capital. Entretanto, Kalemli-Özcan (2019) ressalta que melhorias nas práticas de governança corporativa podem mitigar o fluxo de saída de capital nos países afetados pela normalização da política monetária americana.

As intercorrências do mercado americano impactaram os mercados financeiros de inúmeros países (DE VIJLDER, 2016). Contudo, para que os investidores forneçam capital às empresas é necessário a garantia de que elas serão geridas com eficiência e transparência (MORCK; STEIER, 2005). Com isso, espera-se que as práticas de governança corporativa orientem os gestores em suas decisões em ambientes desafiadores, alinhando seus interesses com aqueles dos acionistas e credores (SHLEIFER; VISHNY, 1997). A ocorrência desses eventos criou um ambiente desafiador para a sobrevivência das corporações e para a geração de riqueza aos acionistas. As bases teóricas utilizadas em pesquisas sobre a governança corporativa após tais eventos de estresse no mercado americano permitem melhor compreender as interpretações e conclusões dos autores de tais estudos. O entendimento desses estudos possibilita conhecer aprimoramentos que possam ser efetuados nas práticas de governança corporativa para que haja aumento da segurança dos investidores. Nesse contexto, questionase: quais as bases teóricas das pesquisas em governança corporativa, considerando os períodos marcados pelos eventos de estresse financeiro ocorridos nos Estados Unidos?

Neste trabalho foram investigadas as bases teóricas dos estudos sobre a governança corporativa por meio de mapeamento bibliométrico utilizando artigos obtidos junto a base Web of Science. Os artigos podem ter sido publicados em periódicos nacionais ou estrangeiros, desde que tenham atendido às palavras-chave selecionadas, em língua inglesa. O objetivo do trabalho foi identificar as bases teóricas mais utilizadas nas pesquisas em governança corporativa nos períodos iniciados por eventos de estresse financeiro nos Estados Unidos. De acordo com Rossoni (2009), Maranho, da Fonseca e Frega (2016) e Kalemli-Özcan (2019), devido à ocorrência dos eventos relatados, verificou-se a necessidade de melhorias nas práticas de governança corporativa. É razoável acreditar que tais melhorias sejam o fruto do surgimento de novas propostas de práticas de governança corporativa apresentadas na literatura, caracterizando a relevância desta pesquisa.

Este estudo contribui para a literatura em Finanças ao apresentar as fundações das pesquisas sobre a governança corporativa por meio de mapeamento bibliométrico, podendo auxiliar as futuras pesquisas ao delinear as bases teóricas utilizadas após os eventos de estresse financeiro relatados. Os estudos bibliométricos até então publicados sobre contabilidade e finanças não abordaram o tema governança corporativa relacionado com os eventos que marcam períodos de crise financeira. Os estudos bibliométricos sobre governança corporativa publicados são gerais, sem relação a qualquer evento macroeconômico. Ademais, o presente estudo representa um avanço por se tratar de uma análise bibliométrica utilizando a técnica de mapeamento bibliométrico.

\section{GOVERNANÇA CORPORATIVA}

\subsection{ORIGEM DOS ESTUDOS E CONCEITOS}


Após a II Guerra, já era verificada a dispersão entre a propriedade e o controle nas empresas americanas, conforme registrado por Berle e Means (1932), que foi, pouco a pouco, tornando-se característica comum entre as empresas de outros países. Com a abertura do capital nas bolsas de valores, as empresas passaram a ter um conjunto de proprietários que não influenciavam diretamente a tomada de decisão, à exceção do acionista majoritário que frequentemente ocupava um cargo de liderança na gestão (IBCG, 2018). A separação entre a propriedade e o controle é, para Fama e Jensen (1983), a separação entre a "tomada de decisão" e a "exposição ao risco" que é observado principalmente nas grandes empresas onde os agentes que tomam a decisão, provavelmente não tem sua riqueza substancialmente afetada pela decisão tomada.

O conceito de governança corporativa pode diferir conforme o autor. Para Shleifer e Vishny (1997), a governança corporativa é formada por mecanismos que asseguram o retorno dos investimentos aos credores, enquanto para Silveira (2006), trata-se de um "sistema pelo qual as sociedades são dirigidas e monitoradas". Entretanto, convergem de alguma forma para práticas que devem ser implementadas, possibilitando o aumento da riqueza dos acionistas por meio de maior transparência das informações. Conforme o Instituto Brasileiro de Governança Corporativa IBCG (2018), os investidores se dispõem a pagar mais por empresas que adotam boas práticas de governança corporativa se "tais práticas não apenas favorecessem os interesses de seus proprietários, mas também a longevidade das empresas".

\subsection{BASES TEÓRICAS E ABORDAGENS DOS ESTUDOS}

Nessa seção serão apresentadas as abordagens e bases teóricas dos artigos revisados a seguir: Teoria de Agência, Teoria dos Contratos, assimetria informacional, Teoria da Sinalização, Teoria da Estrutura de Capital, Teoria da Hierarquização das Fontes de Financiamento, Stewardship Theory, Stakeholder Theory, efeito entrincheiramento, Teoria Institucional, dentre outras.

Em seu artigo seminal, Jensen e Meckling (1976) detalham os custos que surgem quando o proprietário-gestor da empresa decide levantar recursos através da obtenção de capital externo. Estes problemas de agência, resultantes da separação da propriedade e do controle, formam o ambiente onde irão incidir as boas práticas de governança corporativa (CHUNG; WRIGHT; KEDIA, 2003). Davis, Schoorman e Donaldson (1997) afirmam que a Teoria de Agência se apresenta como o paradigma dominante nas pesquisas sobre governança corporativa. A implementação de práticas de governança corporativa tende a reduzir os conflitos de agência, na tentativa de alinhar as expectativas do principal à tomada de decisão pelo gestor através da direção, monitoramento e incentivo (IUDÍCIBUS; LOPES, 2004).

Hart (1995) complementa que a governança corporativa é um mecanismo que assegura a eficácia da tomada de decisões que não foram previstas no contrato inicial. Pela ótica da Teoria dos Contratos são investigados os arranjos entre os vários agentes com vistas a reduzir a incerteza da relação contratual, alinhando as expectativas do contratante e do contratado em virtude da possibilidade de existência de assimetria informacional e conflitos de agência, que está intimamente ligada à decisão de contratar um gestor profissional para administrar a empresa.

Ao abordar o estudo da estrutura de capital na figura de uma estrutura financeira ótima, Durand (1952) alerta que o valor de uma firma endividada seria maior do que a de uma firma sem dívidas. Posteriormente, Modigliani e Miller (1958), propuseram que o custo de capital de uma empresa não dependeria de sua estrutura de capital. $\mathrm{O}$ modelo proposto se baseia em um mundo teórico onde os mercados são perfeitos e em equilíbrio, sendo o valor da empresa determinado pela geração de resultados e pelo risco de seus ativos. DeAngelo e Masulis (1980) fazem críticas às proposições de Modigliani e Miller, afirmando que estas proposições não se 
sustentariam em um ambiente real, na presença de custos de falência, custos de agência, regras tributárias, dentre outros. A alavancagem seria relevante para a firma e teria impacto em seu valor.

Akerlof (1978) investigou as implicações no mercado na presença de assimetria informacional, ou seja, quando duas partes têm conhecimento da informação em níveis diferentes. Através da estrutura de capital da empresa, Ross (1977) e Brealey, Leland e Pyle (1977) demonstraram que a sinalização ao mercado poderia reduzir a assimetria informacional, na medida em que uma informação detida pelos gestores poderia ser transmitida através do aumento do endividamento. Brealey, Leland e Pyle (1977) consideram que a determinação do empresário em investir em seu projeto pode sinalizar ao mercado que se trata de um projeto de qualidade. Já o modelo proposto por Miller e Rock (1985) sugere que os gestores sinalizam aos investidores uma informação privada à empresa, na medida em que maior lucro seria compreendido, provavelmente, por maior capacidade de investimento e pagamento de dividendos. Assim, os gestores utilizam o aumento do payout como uma forma de reduzir a assimetria informacional entre gestores e acionistas/investidores.

Por meio da Teoria da Hierarquização das Fontes de Financiamento (Pecking Order Theory) Myers e Majluf (1984) propõem que, em ambientes onde ocorre a assimetria informacional, as empresas deveriam financiar os novos projetos conforme uma hierarquia das fontes de financiamento utilizando-se, nesta ordem, (i) da retenção de dividendos, (ii) de emissão de dívidas ou (iii) de aumento de capital. Desta forma, a decisão de financiamento seria uma forma de reduzir a assimetria informacional, pois dependendo da forma com que a empresa estivesse se financiando, sinalizaria ao mercado o grau de necessidade de capital.

Davis, Schoorman e Donaldson (1997) consideram a Teoria de Agência uma abordagem econômica para os estudos de governança corporativa, que descreve os subordinados como individualistas, oportunistas e egoístas, em comparação com as abordagens sociológicas e psicológicas como a Stewardship Theory, que descreve os subordinados como coletivistas, próorganizacionais e confiáveis. Os autores destacam que em pesquisas anteriores ocorria uma polarização entre a Stewardship Theory e a Teoria de Agência, com autores considerando ora uma correta, ora outra. Entretanto, estes autores sugerem que esta polarização não é positiva, pois há casos em que a Teoria de Agência pode ser mais indicada para investigar os conflitos existentes, enquanto a Stewardship Theory poderia ser mais apropriada em outros casos.

Ayuso, Rodríguez, García-Castro e Ariño (2014) afirmam que a Stakeholder Theory apresenta uma estrutura teórica apropriada aos estudos de assuntos corporativos relacionados à sociedade, sugerindo novas abordagens aos estudos de governança corporativa com origens em abordagens sociológicas. Os stakeholders, de acordo com Freeman e McVea (2001), são grupos ou indivíduos que afetam ou são afetados pelos objetivos perseguidos por uma organização. Conforme Freeman e McVea (2001), os gestores devem formular e implementar processos no sentido de atender a todos os grupos que tenham algum tipo de interesse ou sofram algum impacto em virtude das atividades da organização. Desta forma a Stakeholder Theory muda o foco da análise em que os gestores trabalham em favor dos interesses de seus acionistas para uma análise mais ampla, em que o foco torna-se entender as expectativas e valores de certos grupos externos à empresa (AYUSO et al, 2014).

De outra forma, a concentração societária pode possibilitar que os controladores expropriem a riqueza dos acionistas minoritários através do pagamento de benefícios e salários elevados, transações duvidosas ou a recusa a fusões e/ou aquisições que poderiam ser vantajosas aos acionistas minoritários, mas que poderia levar à demissão do gestor. $\mathrm{O}$ efeito entrincheiramento é o resultado dos métodos utilizados pelos gestores para aumentar seu poder em benefício próprio. Morck, Shleifer e Vishny (1988) afirmaram que, quando os gestores aumentam significativamente sua participação na propriedade da empresa, torna difícil o 
monitoramento de suas decisões de forma efetiva, refletindo em uma redução da performance da empresa. Esta ocorrência, os autores definiram como "efeito entrincheiramento". Bebchuk, Cohen e Ferrell (2008) encontraram evidências de que um aumento no índice de entrincheiramento está associado a uma redução significante do valor da firma.

Outras bases teóricas podem ser observadas nos estudos sobre a governança corporativa. A Teoria Institucional teve início por meio das proposições de Meyer e Rowan (1977) sobre o institucionalismo. Os autores afirmam que várias organizações refletem em suas estruturas, os mitos institucionalizados na sociedade, pois incorporaram as práticas e procedimentos racionalizados, em suas práticas. Com isto, as organizações aumentam sua legitimidade, mesmo que as práticas e procedimentos adotados não sejam eficazes. Todavia, pela perspectiva da Teoria Neo-Institucional é modificado o foco da visão individual da eficiência de cada mecanismo de governança corporativa para entender como os mecanismos afetam a firma como um todo, aos olhos do mercado (BELL; FILATOTCHEV; AGUILERA, 2014).

Todavia, são várias as teorias e abordagens que podem ser observadas, mesmo que de forma incipiente, nos estudos sobre governança corporativa. Em seu artigo, Stulz (2005) afirma que todos os investidores correm o risco de serem expropriados pelo Estado, mas que os investidores externos correm o risco adicional de também serem expropriados por aquele que controla a empresa, que pode ser tanto um gestor como um acionista controlador. Este panorama de risco de dupla expropriação dos acionistas é chamado pelo autor de Twin Agency Theory. Ainda podem ser observadas, nos estudos, referências a outras bases teóricas e abordagens, mas em menor intensidade. Dentre elas destacam-se a Complimentary and Substitution Perspectives, Behavioral Theory of Firm, Innovation Theory, Efficiency Theory, Proprietary Costs Theory, Legitimacy Theory, Market Learning Theory, Resource-Based View, KnowledgeBased View e Resource Dependency Theory.

\section{ASPECTOS METODOLOGICOS E AMOSTRAGEM}

\subsection{METODOLOGIA}

Nesta pesquisa foram investigadas as bases teóricas e abordagens observadas nos estudos sobre a governança corporativa por meio de mapeamento bibliométrico utilizando artigos publicados durante o período de 2000 a 2018. Esta técnica permite ao pesquisador mapear o estado da arte de uma determinada área por meio da caracterização de parâmetros bibliométricos (DE OLIVEIRA et al, 2019) com base em uma matriz de co-ocorrência, (SINKOVICS, 2016). Assim, é observado em um mapa a distância entre os nós da rede bibliográfica que representa a relação existente entre as pesquisas (PALLUDETO; FELIPINI, 2019).

Para realizar este estudo foi utilizado o software gratuito VOSviewer (Visualization of Similarities Viewer) desenvolvido por Van Eck e Waltman (2010), disponível em www.vosviewer.com. Pesquisas recentes como García-Machado (2018), Palludeto e Felipini (2019), de Oliveira et al. (2019), Burton, Kumar e Pandey (2020) fizeram uso deste software cuja principal característica é a análise e visualização de um grande conjunto de dados bibliográficos considerando uma abordagem distance-based. Com a utilização deste software, as seguintes análises serão realizadas por meio de mapeamento bibliométrico:

(i) Rede Bibliométrica de Coautoria - Observa como as pesquisas em governança corporativa se distribuem no mundo e os laços existentes entre os países de publicação;

(ii) Análise das Citações - Identifica as três pesquisas mais citadas pelos artigos em cada período da amostra, em duas formas distintas: tanto as pesquisas citadas pelos artigos no período em análise, quanto as pesquisas citadas e publicadas no período analisado. 
(iii) Análise de Cocitações de Referências - Observa as relações entre publicações distintas, pois quanto maior for a quantidade de vezes em que dois artigos são cocitados por um terceiro, mais forte é a relação de cocitação entre os dois trabalhos cocitados (PALLUDETO; FELIPINI, 2019).

(iv) Acoplamento Bibliográfico - Identifica as redes de conhecimento mais atuais ao observar a proximidade existente entre duas publicações.

Ressalta-se que foi adotado um número mínimo de citações para formação dos clusters de forma discricionária, conforme procedimento realizado por García-Machado (2018). O objetivo deste procedimento é a formação de pelo menos quatro clusters por análise, onde serão verificados manualmente, em média, $15 \%$ dos artigos de cada cluster para identificar as abordagens e teorias de base utilizadas nos trabalhos, seguindo a ordem do mais citado para o menos citado. Um número reduzido de clusters auxilia o pesquisador na identificação dos principais temas em um mapa bibliométrico (CASSELL; CUNLIFFE; GRANDY, 2017).

\subsection{DADOS DA AMOSTRA}

A amostra desta pesquisa é formada por 2.965 artigos publicados em inglês, do ano 2000 a 2018. Estes artigos foram obtidos junto à base de dados Web of Science, atendendo aos seguintes critérios: (i) artigos classificados nas áreas economics, business, public administration, management e business finance (ii) e que continham no título as palavras "corporate governance". Importante ressalvar que os parâmetros de seleção descritos não contemplam a classificação epistemológica dos artigos analisados.

O período da amostra foi subdividido em três períodos distintos, pois conforme De Vijlder (2016), as intercorrências do mercado americano normalmente causam impactos em inúmeros países do mundo. Por meio desta subdivisão, serão observados três períodos em função de eventos financeiros ocorridos nos Estados Unidos. O primeiro período, de 2000 a 2007, foi marcado pela supervalorização dos ativos que culminou na bolha das pontocom, além de fraudes contábeis ocorridas em diversas corporações. O segundo período foi de 2008 até 2013, sendo este último, o ano que marcou o início do fim do Quantitative Easing - mecanismo de compra de títulos introduzido por meio da política monetária não convencional americana que visava, inicialmente, evitar o colapso da economia nos Estados Unidos e posteriormente, estimular a retomada dos indicadores econômicos à níveis considerados normais pelo banco central americano. O terceiro, de 2014 a 2018, caracterizado pelo início da normalização da política monetária americana em um período marcado por alta liquidez, até então inexistente (BANK FOR INTERNATIONAL SETTLEMENTS, 2017).

A ocorrência desses eventos criou um ambiente desafiador tanto para a sobrevivência das corporações quanto para a geração de riqueza aos acionistas. As bases teóricas utilizadas em pesquisas sobre a governança corporativa após tais eventos de estresse possibilitam compreender as interpretações e conclusões dos autores dos estudos, que podem ter como resultado aprimoramentos de tais práticas visando o aumento da segurança dos investidores. A seguir, tabela 1 encontra-se a quantidade de artigos por período, a evolução da taxa de crescimento das publicações, assim como a média e o desvio padrão.

Tabela 1 - Descrição da amostra, por período.

\begin{tabular}{lllll}
\hline Período & Artigos & Crescimento & Média de Artigos & Desvio Padrão \\
\hline 2000 a 2007 & 699 & - & 87.38 & 31.89 \\
2008 a 2013 & 1057 & $51.22 \%$ & 176.17 & 32.33 \\
2014 a 2018 & 1209 & $14.38 \%$ & 241.80 & 49.73 \\
\hline TOTAL & 2965 & & & \\
\hline
\end{tabular}

Fonte: elaborado pelos autores.

É possível notar que as pesquisas sobre governança corporativa aumentaram de 2000 a 2009 e passaram a oscilar daí em diante, mas dentro de um canal de alta, atingindo seu pico em 
2015, conforme observado na figura 1 . Se for considerado o tempo existente entre a submissão de um artigo até a sua aprovação em um periódico, os picos ocorridos em 2009 e 2015, encontram-se próximos aos eventos mencionados como determinantes para a formação dos períodos desta pesquisa. No ano 2000, início do período analisado, apenas 58 artigos atenderam aos critérios desta pesquisa.

Figura 1 - Quantidade de artigos publicados que atenderam aos critérios da pesquisa.

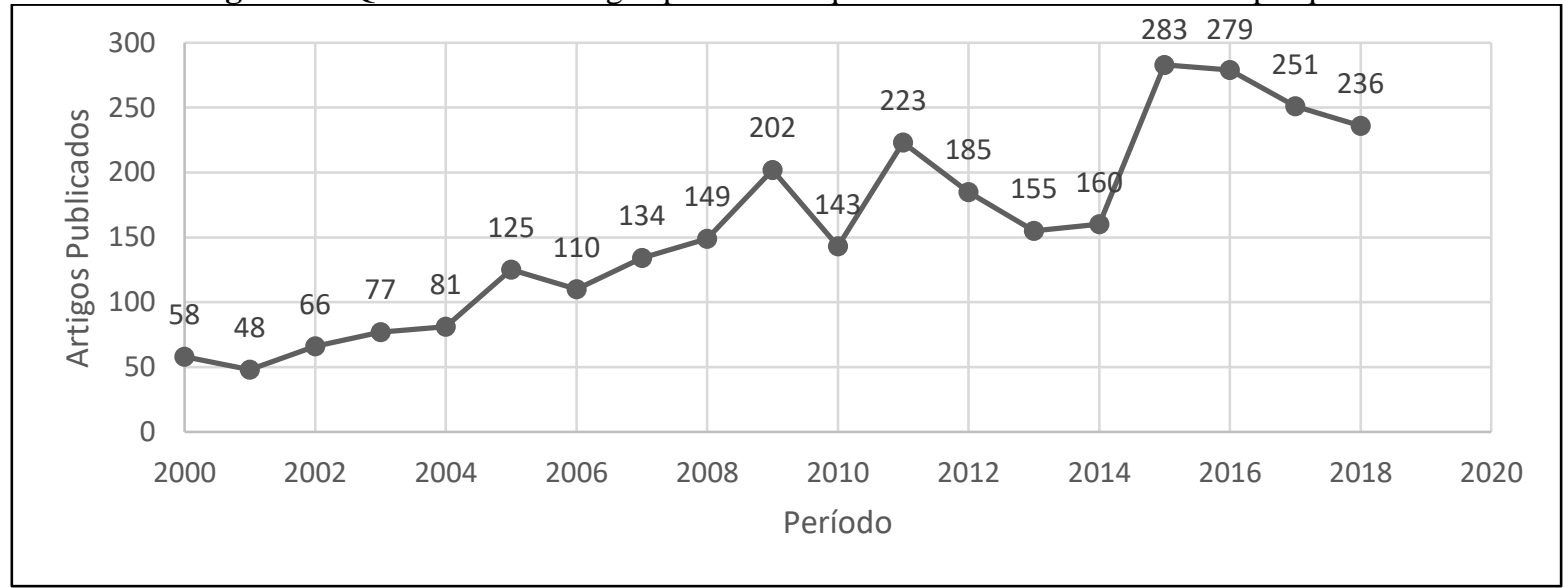

Fonte: elaborado pelos autores.

Em 2018, término do período analisado, 236 artigos atenderam aos mesmos critérios citados anteriormente, indicando um crescimento nas pesquisas sobre governança corporativa na ordem de 406,90\% entre o início e o término do período analisado.

\section{ANÁLISE DOS RESULTADOS}

\subsection{REDE BIBLIOMÉTRICA DE COAUTORIA}

Pela análise da rede bibliométrica de coautoria observa-se como as pesquisas em governança corporativa se distribuem no mundo e os laços existente entre os países de publicação. Na figura 2 pode-se observar a colaboração entre os países, determinada pelo número de publicações que tenham em conjunto (VAN ECK; WALTMAN, 2014). Nesta representação gráfica, cada círculo representa um país e quanto maior o tamanho do círculo, maior a influência deste na rede de colaboração. Por sua vez, a distância e a largura da ligação refletem o grau de colaboração entre os países.

Figura 2 - Rede bibliométrica de coautoria.

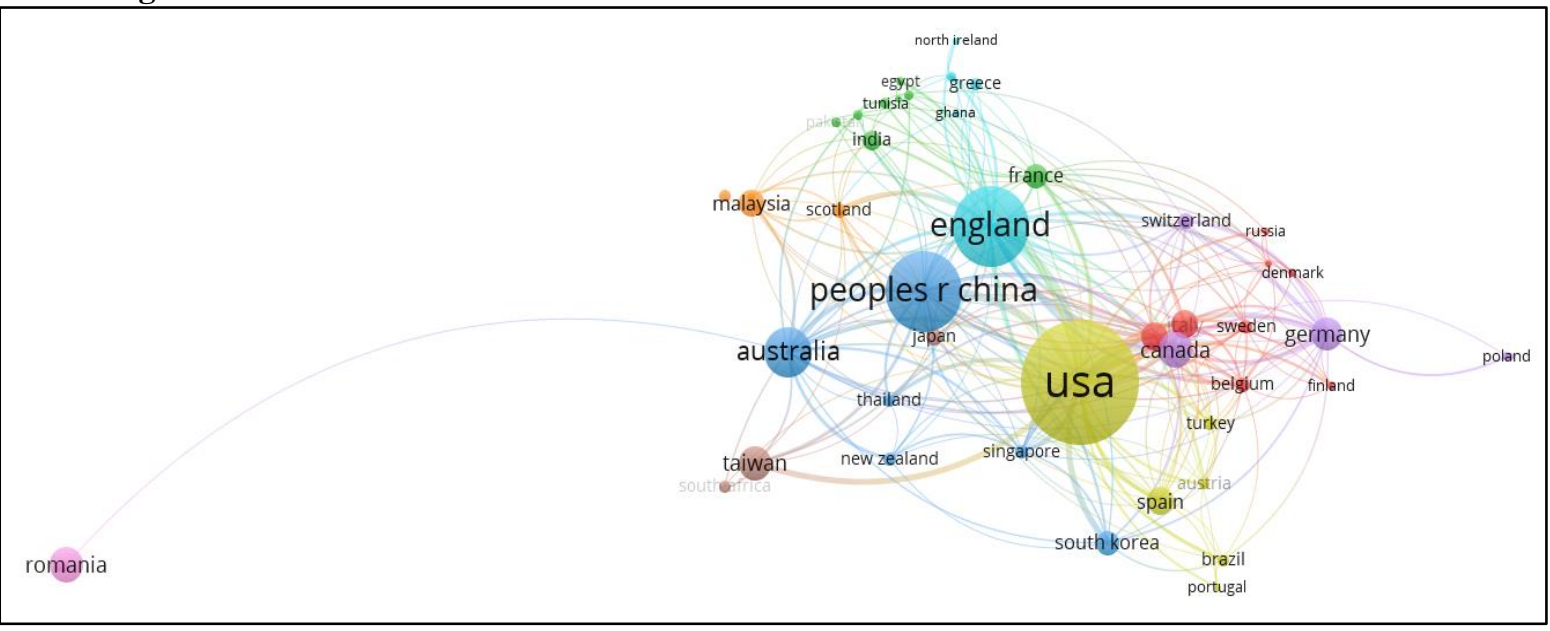

Fonte: elaborado pelos autores.

Destaca-se que os Estados Unidos (USA) colaboram com quase todos os países da rede, assim como a Inglaterra (England) e a República Popular da China (People's Republic of 
Panorama da Literatura sobre a Governança Corporativa: uma Análise Bibliométrica das Bases Teóricas e Abordagens mais Utilizadas em Artigos

China), pois eles têm a maior influência na rede de colaboração. O relacionamento apresentado sugere que os Estados Unidos e a Inglaterra disseminam as práticas de governança corporativa do sistema anglo-saxão, que são adaptadas, aceitas ou rejeitadas pelos outros países, possivelmente em função de seus sistemas legal, econômico-financeiro e cultural e de práticas locais de gestão.

\subsection{ANÁLISE DAS CITAÇÕES}

As três pesquisas mais citadas pelos artigos em cada período da amostra encontram-se relacionadas nos quadros 1 e 2. A diferença entre esses quadros é explicada conforme exemplo, a seguir. No período de 2000 a 2007, no quadro 1, estão relacionados os artigos que foram mais citados pelos artigos publicados do ano 2000 a 2007. Pode-se identificar o artigo de Jensen e Meckling (1976), como o mais citado.

Quadro 1 - Artigos mais citados pelos artigos da amostra de cada período.

\begin{tabular}{|c|c|c|c|c|c|}
\hline & Autor e Periódico & Ano & Título & Citações & Percentual \\
\hline \multicolumn{6}{|c|}{ Período: 2000 a 2007} \\
\hline 1 & $\begin{array}{l}\text { Jensen e Meckling - Journal } \\
\text { of Financial Economics }\end{array}$ & 1976 & $\begin{array}{l}\text { Theory of the firm: Managerial behavior, } \\
\text { agency costs and ownership structure }\end{array}$ & 104 & $45.61 \%$ \\
\hline 2 & $\begin{array}{l}\text { Shleifer e Vishny - Journal } \\
\text { of Finance }\end{array}$ & 1997 & A Survey of Corporate Governance & 71 & $31.14 \%$ \\
\hline \multirow[t]{2}{*}{3} & Berle e Means - Macmillam & 1932 & $\begin{array}{l}\text { For whom corporate managers are } \\
\text { trustees: a note }\end{array}$ & 53 & $23.25 \%$ \\
\hline & & & Total: & 228 & $100.00 \%$ \\
\hline & \multicolumn{5}{|l|}{ Período: 2008 a 2013} \\
\hline 1 & $\begin{array}{l}\text { Jensen e Meckling - Journal } \\
\text { of Financial Economics }\end{array}$ & 1976 & $\begin{array}{l}\text { Theory of the firm: Managerial behavior, } \\
\text { agency costs and ownership structure }\end{array}$ & 161 & $40.66 \%$ \\
\hline 2 & $\begin{array}{l}\text { Gompers, Ishii e Metrick - } \\
\text { Quaterly Journal of } \\
\text { Economics }\end{array}$ & 2003 & Corporate Governance and Equity Prices & 124 & $31.31 \%$ \\
\hline \multirow[t]{2}{*}{3} & $\begin{array}{l}\text { Shleifer e Vishny - Journal } \\
\text { of Finance }\end{array}$ & 1997 & A Survey of Corporate Governance & 111 & $28.03 \%$ \\
\hline & & & Total: & 396 & $100.00 \%$ \\
\hline & \multicolumn{5}{|l|}{ Período: 2014 a 2018} \\
\hline 1 & $\begin{array}{l}\text { Jensen e Meckling - Journal } \\
\text { of Financial Economics }\end{array}$ & 1976 & $\begin{array}{l}\text { Theory of the firm: Managerial behavior, } \\
\text { agency costs and ownership structure }\end{array}$ & 256 & $44.52 \%$ \\
\hline 2 & $\begin{array}{l}\text { Shleifer e Vishny - Journal } \\
\text { of Finance }\end{array}$ & 1997 & A Survey of Corporate Governance & 172 & $29.91 \%$ \\
\hline \multirow[t]{3}{*}{3} & $\begin{array}{l}\text { Gompers, Ishii e Metrick - } \\
\text { Quaterly Journal of } \\
\text { Economics }\end{array}$ & 2003 & Corporate Governance and Equity Prices & 147 & $25.57 \%$ \\
\hline & & & Total: & 575 & $100.00 \%$ \\
\hline & & & Total de artigos dos três períodos: & 1199 & $100.00 \%$ \\
\hline
\end{tabular}

Fonte: elaborado pelos autores.

Já no quadro 2, no mesmo período de 2000 a 2007, estão relacionados os artigos que foram mais citados, "mas que também foram publicados no período analisado, do ano 2000 a 2007”. Portanto, o artigo mais citado no período de 2000 a 2007 no quadro 2 foi o trabalho de Gompers, Ishii e Metrick (2003). 
Panorama da Literatura sobre a Governança Corporativa: uma Análise Bibliométrica das Bases Teóricas e Abordagens mais Utilizadas em Artigos

Quadro 2 - Artigos mais citados de cada período da amostra.

\begin{tabular}{|c|c|c|c|c|c|}
\hline & Autor e Periódico & Ano & Título & Citações & Percentual \\
\hline & \multicolumn{5}{|l|}{ Período: 2000 a 2007} \\
\hline 1 & $\begin{array}{l}\text { Gompers, Ishii e Metrick - } \\
\text { Quaterly Journal of } \\
\text { Economics }\end{array}$ & 2003 & $\begin{array}{l}\text { Corporate Governance and Equity } \\
\text { Prices }\end{array}$ & 2,161 & $47.80 \%$ \\
\hline 2 & $\begin{array}{l}\text { La Porta, Lopez-de-Silanes, } \\
\text { Shleifer e Vishny - Journal of } \\
\text { Financial Economics }\end{array}$ & 2000 & $\begin{array}{l}\text { Agency problems and dividend policies } \\
\text { around the world }\end{array}$ & 1,663 & $36.78 \%$ \\
\hline \multirow[t]{2}{*}{3} & $\begin{array}{l}\text { Aguilera e Jackson - Academy } \\
\text { of Management Review }\end{array}$ & 2003 & $\begin{array}{l}\text { The cross-national diversity of } \\
\text { corporate governance: Dimensions and } \\
\text { determinants }\end{array}$ & 697 & $15.42 \%$ \\
\hline & & & Total: & 4,521 & $100.00 \%$ \\
\hline & \multicolumn{5}{|l|}{ Período: 2008 a 2013} \\
\hline 1 & $\begin{array}{l}\text { Bebchuk, Cohen e Ferrell - } \\
\text { Review of Financial Studies }\end{array}$ & 2008 & $\begin{array}{l}\text { What Matters in Corporate } \\
\text { Governance? }\end{array}$ & 773 & $45.26 \%$ \\
\hline 2 & $\begin{array}{l}\text { Young, Peng, Ahlstrom, } \\
\text { Bruton e Jiang - Journal of } \\
\text { Management Studies }\end{array}$ & 2008 & $\begin{array}{l}\text { Corporate governance in emerging } \\
\text { economies: A review of the principal- } \\
\text { principal perspective }\end{array}$ & 534 & $31.26 \%$ \\
\hline \multirow[t]{2}{*}{3} & $\begin{array}{l}\text { Adams, Hermalin, Weisbach - } \\
\text { Journal of Economic } \\
\text { Literature }\end{array}$ & 2010 & $\begin{array}{l}\text { The role of boards of directors in } \\
\text { corporate governance: A conceptual } \\
\text { framework and survey }\end{array}$ & 401 & $23.48 \%$ \\
\hline & & & Total: & 1,708 & $100.00 \%$ \\
\hline & \multicolumn{5}{|l|}{ Período: 2014 a 2018} \\
\hline 1 & $\begin{array}{l}\text { Misangyi e Acharya - } \\
\text { Academy of Management } \\
\text { Journal }\end{array}$ & 2014 & $\begin{array}{l}\text { Substitutes or complements? A } \\
\text { configurational examination of } \\
\text { corporate governance mechanisms }\end{array}$ & 106 & $40.93 \%$ \\
\hline 2 & $\begin{array}{l}\text { Bell, Filatotchev e Aguilera - } \\
\text { Academy of Management } \\
\text { Journal }\end{array}$ & 2014 & $\begin{array}{l}\text { Corporate governance and investors' } \\
\text { perceptions of foreign IPO value: An } \\
\text { institutional perspective }\end{array}$ & 85 & $32.82 \%$ \\
\hline \multirow[t]{3}{*}{3} & $\begin{array}{l}\text { Jizi, Salama, Dixon e Stratling } \\
\text { - Journal of Business Ethics }\end{array}$ & 2014 & $\begin{array}{l}\text { Corporate governance } \\
\text { and corporate social responsibility } \\
\text { disclosure: Evidence from the US } \\
\text { banking sector }\end{array}$ & 68 & $26.25 \%$ \\
\hline & & & Total: & 259 & $100.00 \%$ \\
\hline & & & Total de artigos dos três períodos: & 2,323 & $100.00 \%$ \\
\hline
\end{tabular}

Fonte: elaborado pelos autores.

Expandindo a análise para os dez artigos mais citados em cada período, oito artigos são coincidentes para todos os períodos da amostra e representam, em média, 82,37\% das citações de cada período. Em outras palavras, em cada período, em média, 82,37\% das citações se referem às mesmas bases teóricas que também são utilizadas nos outros períodos da amostra. Isto sugere que uma grande parte das bases teóricas utilizadas nas pesquisas sobre governança corporativa se originam de artigos seminais "consagrados". Entretanto, existe uma parcela de artigos $(17,63 \%)$ que pode levar ao surgimento de novas teorias ou propostas, visando minimizar os problemas enfrentados nas corporações relativos aos conflitos existentes. Podese notar que a Teoria de Agência se apresenta como o paradigma dominante nas pesquisas sobre governança corporativa. Outras teorias e abordagens observadas foram a Teoria da Estrutura de Propriedade, Teoria da Estrutura de Capital, Teoria dos Contratos e a assimetria informacional. Nas pesquisas sobre a governança corporativa foi observada a aplicação de mais de uma abordagem ou base teórica. Apesar disso, a maioria das pesquisas que utilizam mais de uma base teórica, utilizam a Teoria de Agência como uma das teorias de base. 
A seguir, serão apresentadas a análise de cocitação de referências, o acoplamento e uma síntese das abordagens e teorias observadas.

\subsection{ANÁLISE DE COCITAÇÃO DE REFERÊNCIAS}

Uma cocitação ocorre quando dois artigos são citados por um terceiro e assim, quanto maior for a quantidade de vezes em que dois artigos são cocitados por um terceiro, mais forte é a relação de cocitação entre os dois trabalhos cocitados (PALLUDETO; FELIPINI, 2019). Ressalta-se que a cocitação está voltada para identificar as referências utilizadas pelos artigos da amostra. Todavia, como vários dos artigos cocitados foram publicados antes do período de análise desta pesquisa, os artigos cocitados tendem a não fazer parte do período da amostra.

No mapa da rede de cocitação, cada círculo (também chamado de nó) representa um artigo e quanto maior for o tamanho do círculo, maior é a quantidade de cocitações ocorridas. Em relação à ligação entre os círculos, quanto mais grossa a linha que conecta dois artigos, mais forte é a relação de cocitação entre eles. Na análise de cocitações é realizado o agrupamento dos artigos da amostra em clusters, considerando o número mínimo de 40 citações. A figura 3 apresenta a rede de cocitações da amostra desta pesquisa, indicando a formação de 4 clusters.

Figura 3 - Cocitação de referências período 2000 a 2018.

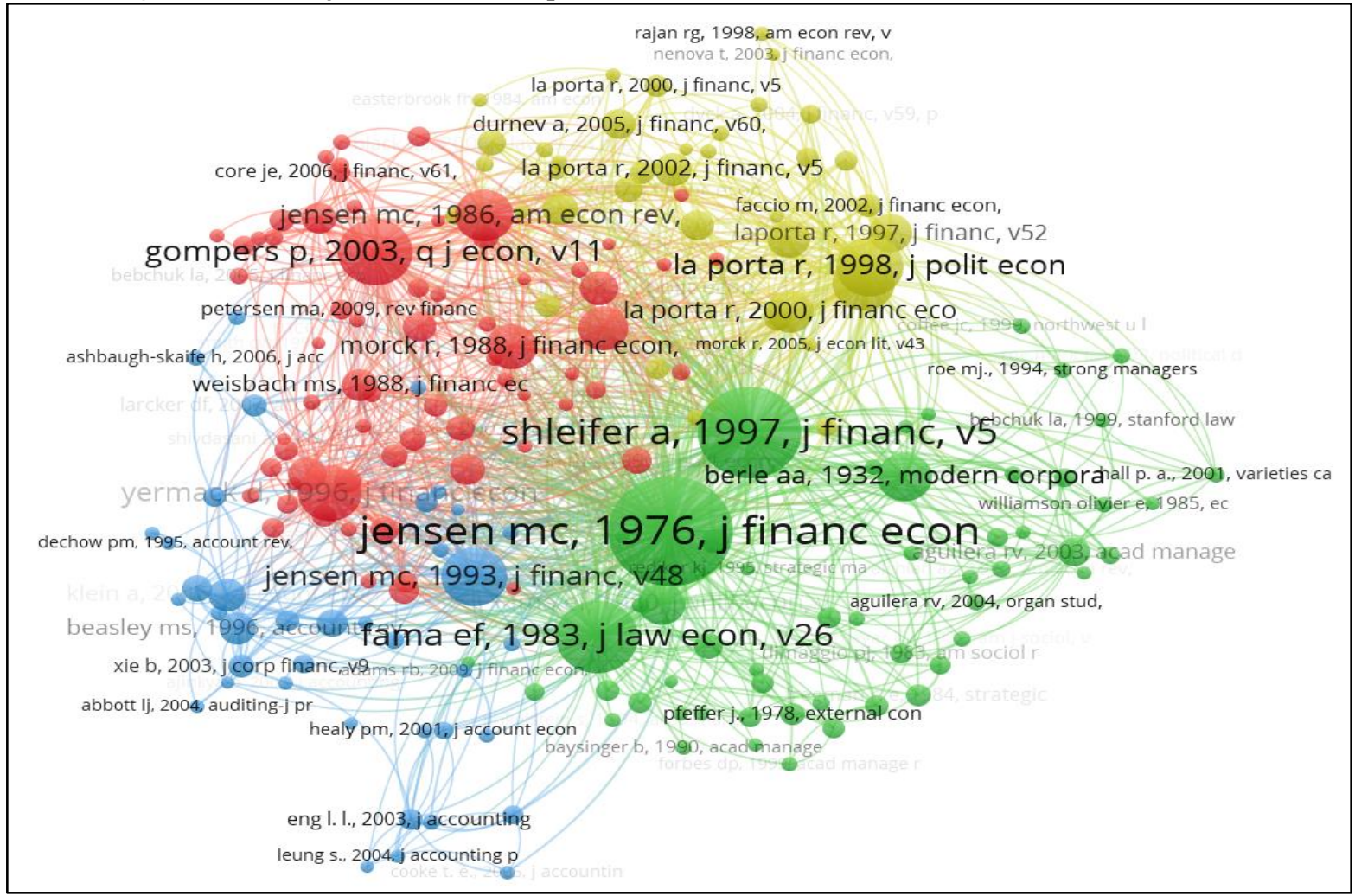

Fonte: elaborado pelos autores.

Foram analisados os artigos que apresentavam os maiores círculos de cada cluster (maior quantidade de cocitações), em seguida, foram analisados os artigos com muitos relacionamentos (muitas linhas que partem do círculo em direção a outros círculos) e posteriormente, os artigos de relacionamentos mais fortes (linhas mais grossas). Desta forma, os clusters foram renomeados como pode ser observado no quadro 3: (i) cluster verde: Teoria de Agência e a Separação da Propriedade e Controle, (ii) cluster vermelho: Estrutura de Governança corporativa e a Performance da Empresa, (iii) cluster azul: Pesquisa Contábil; (iv) cluster amarelo: Pesquisas Cross-Country. 
Panorama da Literatura sobre a Governança Corporativa: uma Análise Bibliométrica das Bases Teóricas e Abordagens mais Utilizadas em Artigos

Quadro 3 - Resumo da cocitação de referências.

\begin{tabular}{|c|c|c|c|c|c|}
\hline Cluster & $\begin{array}{c}\text { Artigo } \\
\text { Principal }\end{array}$ & $\begin{array}{l}\text { Nome } \\
\text { Atribuído }\end{array}$ & Predominância & $\begin{array}{c}\text { Época das } \\
\text { publicações }\end{array}$ & Comentários \\
\hline Verde & $\begin{array}{l}\text { Jensen e } \\
\text { Meckling } \\
(1976), \\
\text { Shleifer e } \\
\text { Vishny } \\
(1997)\end{array}$ & $\begin{array}{l}\text { Teoria de } \\
\text { Agência e a } \\
\text { Separação } \\
\text { da } \\
\text { Propriedade } \\
\text { e Controle }\end{array}$ & $\begin{array}{l}\text { Teoria da Agência, Teoria } \\
\text { da Estrutura de } \\
\text { Propriedade, Teoria dos } \\
\text { Contratos, Teoria da } \\
\text { Estrutura de Capital e } \\
\text { assimetria informacional. }\end{array}$ & $\begin{array}{l}\text { Décadas de } 70 \\
\text { e } 80 \text { com } \\
\text { publicações } \\
\text { na década de } \\
90 \text { e início da } \\
\text { década de } \\
2000 .\end{array}$ & $\begin{array}{l}\text { Cluster dos artigos de } \\
\text { base das pesquisas em } \\
\text { governança } \\
\text { corporativa. }\end{array}$ \\
\hline Vermelho & $\begin{array}{l}\text { Gompers, } \\
\text { Ishii e } \\
\text { Metrick } \\
(2003)\end{array}$ & $\begin{array}{l}\text { Estrutura de } \\
\text { Governança } \\
\text { corporativa e } \\
\text { o } \\
\text { Desempenho } \\
\text { da Empresa }\end{array}$ & $\begin{array}{l}\text { Teoria de Agência, Teoria } \\
\text { da Estrutura de Capital, } \\
\text { Teoria da Estrutura de } \\
\text { Propriedade, Teoria dos } \\
\text { Contratos e efeito } \\
\text { entrincheiramento. }\end{array}$ & $\begin{array}{l}\text { Em sua maior } \\
\text { parte, décadas } \\
\text { de } 80 \text { e } 90 .\end{array}$ & $\begin{array}{l}\text { Percebe-se que as } \\
\text { pesquisas partiram } \\
\text { para uma etapa mais } \\
\text { voltada a encontrar } \\
\text { soluções que } \\
\text { contribuíssem para a } \\
\text { melhora do } \\
\text { desempenho das } \\
\text { empresas. }\end{array}$ \\
\hline Azul & $\begin{array}{l}\text { Jensen } \\
(1993)\end{array}$ & $\begin{array}{l}\text { Pesquisa } \\
\text { Contábil }\end{array}$ & $\begin{array}{l}\text { Assimetria Informacional } \\
\text { e a Teoria da Sinalização. }\end{array}$ & $\begin{array}{l}\text { Década de } 90 \\
\text { e primeira } \\
\text { metade da } \\
\text { década de } \\
2000 .\end{array}$ & $\begin{array}{l}\text { Evidencia o suporte } \\
\text { dado pelas } \\
\text { demonstrações } \\
\text { contábeis em auxiliar } \\
\text { investidores e credores } \\
\text { na tomada de decisão. }\end{array}$ \\
\hline Amarelo & $\begin{array}{l}\text { La Porta et } \\
\text { al. }(1998)\end{array}$ & $\begin{array}{l}\text { Pesquisas } \\
\text { Cross- } \\
\text { Country }\end{array}$ & $\begin{array}{l}\text { Teoria de Agência, Teoria } \\
\text { da Estrutura de Capital, } \\
\text { Estrutura de Propriedade, } \\
\text { mas também foi } \\
\text { observado, em menor } \\
\text { escala, a presença do } \\
\text { efeito entrincheiramento. }\end{array}$ & $\begin{array}{l}\text { Em sua } \\
\text { maioria, } \\
\text { décadas } \\
\text { de } 90 \text { e } 2000 .\end{array}$ & $\begin{array}{l}\text { Similaridades e } \\
\text { diferenças dos } \\
\text { problemas observados } \\
\text { em vários países } \\
\text { visando desenvolver } \\
\text { soluções em função } \\
\text { das práticas observadas } \\
\text { e dos aspectos legais } \\
\text { presentes em cada } \\
\text { economia. }\end{array}$ \\
\hline
\end{tabular}

Fonte: elaborado pelos autores.

Pode-se concluir que, no cluster verde (Teoria de Agência e a Separação da Propriedade e Controle), encontram-se os artigos de base das pesquisas em governança corporativa e, por isso, tem um relacionamento forte com os outros clusters. Apesar de Gompers, Ishii e Metrick (2003) ser um dos principais artigos do cluster vermelho (Estrutura de Governança corporativa e a Performance da Empresa), ele é datado do início dos anos 2000. Isto pode sugerir que após os artigos seminais do cluster verde, as pesquisas partiram para uma etapa mais voltada a encontrar soluções que contribuíssem para a melhora do desempenho das empresas. Do cluster verde, vem a base dos questionamentos, e do cluster vermelho, a busca por soluções, evidenciando o suporte dado pelas demonstrações contábeis acerca do desempenho das empresas em auxiliar investidores e credores na tomada de decisão. Pode-se concluir, conforme Davis, Schoorman e Donaldson (1997), que a Teoria de Agência ainda se apresenta como o paradigma dominante nas pesquisas sobre governança corporativa.

\subsection{ACOPLAMENTO BIBLIOGRÁFICO}

O acoplamento bibliográfico é considerado o oposto da cocitação. De acordo com Kessler (1963), duas publicações estão acopladas bibliograficamente quando uma terceira publicação é citada pelas duas anteriores. Conforme Van Eck e Waltman (2014), quanto mais próximo duas publicações estiverem uma da outra, existirá uma tendência maior destas duas 
publicações citarem uma terceira publicação em comum. A rede de conhecimento baseada na análise do acoplamento bibliográfico, mapeia os trabalhos recentes com base em suas citações, permitindo o estudo de redes de conhecimento mais atuais. A análise do acoplamento bibliográfico dos artigos publicados no período de 2000 a 2007 é apresentado na figura 4, onde pode ser observada a formação de 8 clusters considerando o mínimo de 30 citações.

Figura 4 - Acoplamento bibliográfico, período 2000 a 2007.

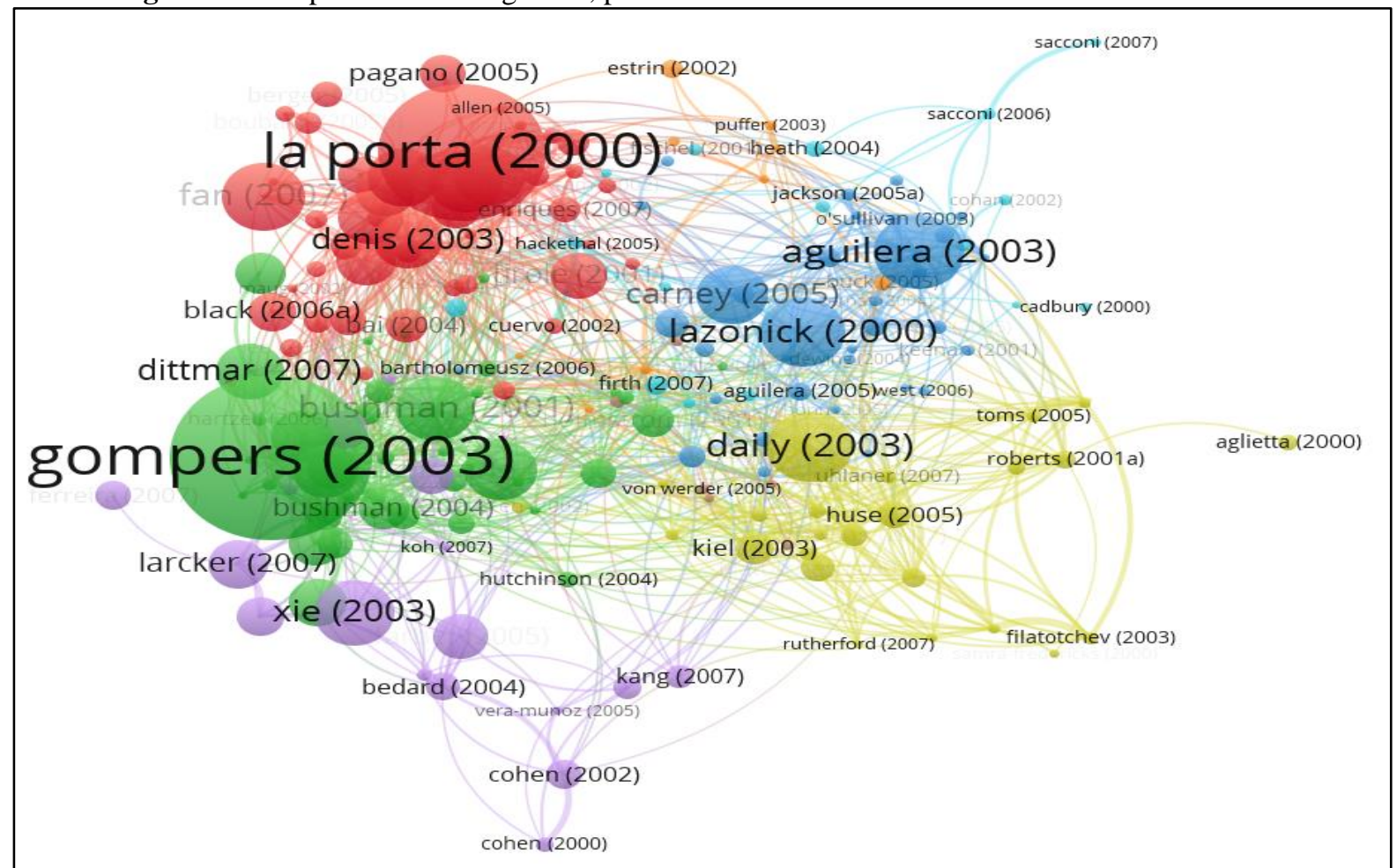

Fonte: elaborado pelos autores.

A proximidade e o relacionamento existente entre os clusters verde e vermelho pode ser um reflexo das teorias dominantes, que são similares. Estes dois clusters são os que apresentam os artigos mais citados do período. São eles La Porta, Lopez-de-Silanes, Shleifer e Vishny (2000) e Gompers, Ishii e Metrick (2003). No quadro 4 são apresentadas as teorias e abordagens observadas através do acoplamento bibliográfico durante o período dos anos 2000 a 2007.

Quadro 4 - Acoplamento bibliográfico, período 2000 a 2007

\begin{tabular}{|lccccccccc|}
\hline & \multicolumn{7}{c}{ Clusters } \\
& Vermelho & Verde & Roxo & Amarelo & Azul & Azul Claro & Laranja & Marrom \\
\hline Teoria de Agência & $\operatorname{sim}$ & $\operatorname{sim}$ & $\operatorname{sim}$ & $\operatorname{sim}$ & $\operatorname{sim}$ & $\operatorname{sim}$ & $\operatorname{sim}$ & sim \\
\hline Teoria da Estrutura de Capital & $\operatorname{sim}$ & $\operatorname{sim}$ & - & - & - & - & - & - \\
\hline Teoria da Sinalização & - & - & $\operatorname{sim}$ & - & - & - & - & - \\
\hline Modern Portfolio Theory & - & - & - & - & - & $\operatorname{sim}$ & - & - \\
\hline $\begin{array}{l}\text { Teoria da Estrutura de } \\
\text { Propriedade }\end{array}$ & $\operatorname{sim}$ & $\operatorname{sim}$ & $\operatorname{sim}$ & $\operatorname{sim}$ & $\operatorname{sim}$ & $\operatorname{sim}$ & $\operatorname{sim}$ & $\operatorname{sim}$ \\
\hline Teoria dos Contratos & $\operatorname{sim}$ & $\operatorname{sim}$ & - & - & $\operatorname{sim}$ & - & - & - \\
\hline Stewardship Theory & - & - & - & $\operatorname{sim}$ & $\operatorname{sim}$ & $\operatorname{sim}$ & - & - \\
\hline Stakeholder Theory & $\operatorname{sim}$ & $\operatorname{sim}$ & - & $\operatorname{sim}$ & $\operatorname{sim}$ & $\operatorname{sim}$ & $\operatorname{sim}$ & - \\
\hline Resource-Based Views & - & - & - & - & $\operatorname{sim}$ & - & - & - \\
\hline Efficiency Theory & - & - & - & - & - & - & - & $\operatorname{sim}$ \\
\hline Theory of Path Dependence & - & - & - & - & $\operatorname{sim}$ & - & - & - \\
\hline Observation Theory & - & - & - & - & - & - & - & sim \\
\hline Resource Dependency Theory & - & - & - & $\operatorname{sim}$ & $\operatorname{sim}$ & $\operatorname{sim}$ & - & -
\end{tabular}


Simões e Souza (2020)

Panorama da Literatura sobre a Governança Corporativa: uma Análise Bibliométrica das Bases Teóricas e Abordagens mais Utilizadas em Artigos

\begin{tabular}{|lcccccccc|}
\hline $\begin{array}{l}\text { Teoria Comportamental dos } \\
\text { Conselhos de Administração }\end{array}$ & - & - & - & $\operatorname{sim}$ & - & - & - \\
\hline Institutional Theory & - & - & - & $\operatorname{sim}$ & $\operatorname{sim}$ & - & - & - \\
\hline Neoinstitutional Theory & - & - & - & - & - & - & $\operatorname{sim}$ \\
\hline Legitimacy Theory & - & - & - & - & - & - & - & $\operatorname{sim}$ \\
\hline Assimetria Informacional & $\operatorname{sim}$ & $\operatorname{sim}$ & $\operatorname{sim}$ & - & $\operatorname{sim}$ & - & - & - \\
\hline Efeito Entrincheiramento & $\operatorname{sim}$ & $\operatorname{sim}$ & $\operatorname{sim}$ & - & $\operatorname{sim}$ & - & $\operatorname{sim}$ & - \\
\hline
\end{tabular}

Fonte: elaborado pelos autores.

A seguir, o mapeamento do acoplamento bibliográfico referente ao período de 2008 a 2013 é apresentada na figura 5. Apesar de terem sido identificados 7 clusters, considerando um mínimo de 30 citações, apenas 4 deles são bem definidos e foram identificados da seguinte forma: cluster vermelho (Performance, dívida e conselho de administração), verde (Direito e Proteção dos acionistas), azul (Multinacionais \& International Business) e amarelo (Pesquisa Contábil).

Figura 1 - Acoplamento bibliográfico, período 2008 a 2013.

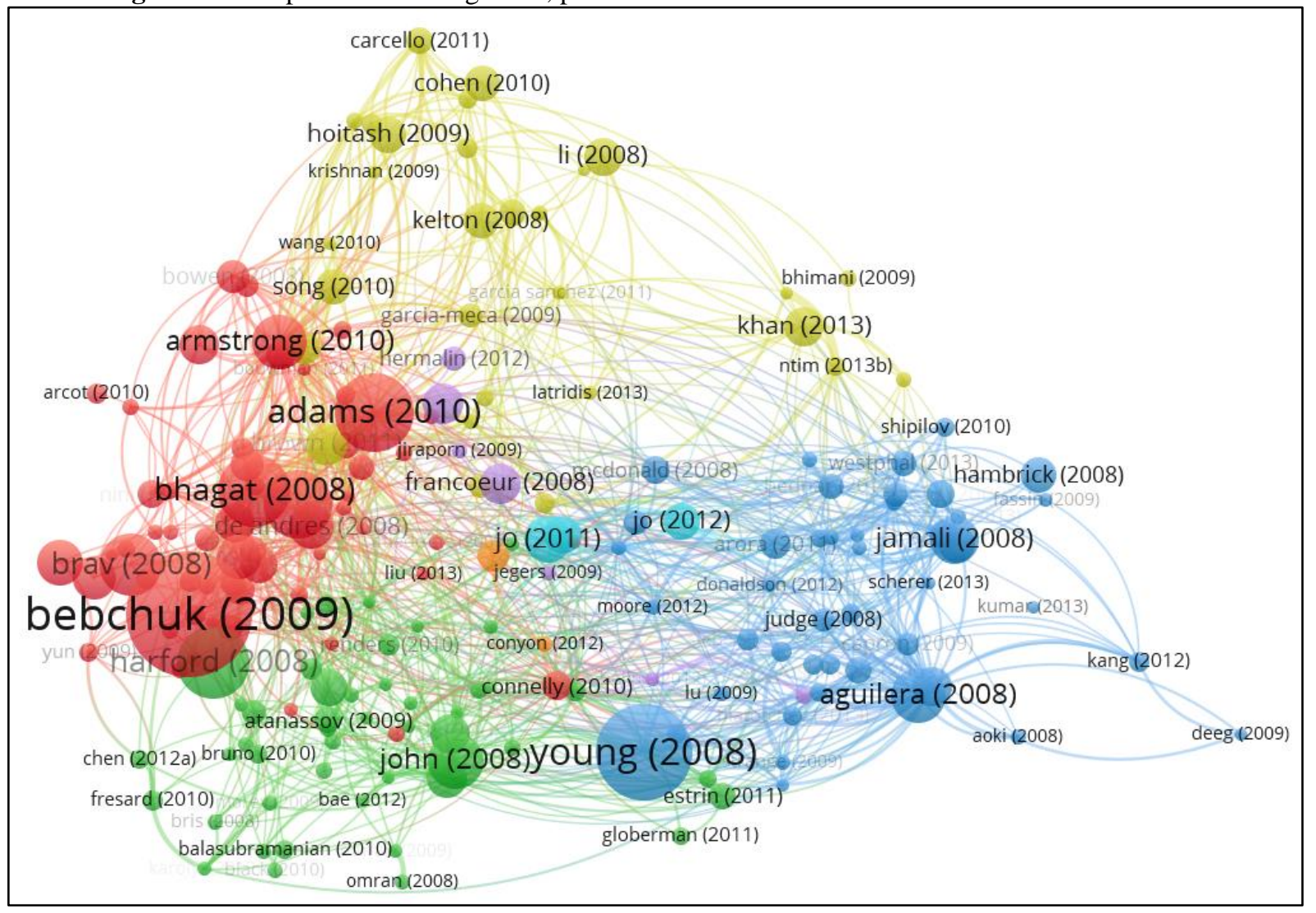

Fonte: elaborado pelos autores.

Nota-se que os clusters roxo (CEO e Conselho de Administração), azul claro (Responsabilidade Social Corporativa) e o laranja (Remuneração do CEO e executivos na China) estão mais dispersos na parte central da figura, sugerindo que as pesquisas destes clusters têm um relacionamento disperso entre as pesquisas dos clusters mais definidos. A quantidade reduzida de artigos nestes clusters pode ser um indício deste comportamento. No quadro 5 é apresentado um resumo com as teorias observadas por meio do acoplamento bibliográfico referente ao período de 2008 a 2013. 
Simões e Souza (2020)

Panorama da Literatura sobre a Governança Corporativa: uma Análise Bibliométrica das Bases Teóricas e Abordagens mais Utilizadas em Artigos

Quadro 5 - Acoplamento bibliográfico, período 2008 a 2013.

\begin{tabular}{|c|c|c|c|c|c|c|c|}
\hline & \multicolumn{7}{|c|}{ Clusters } \\
\hline & Vermelho & Verde & Roxo & Amarelo & Azul & Azul Claro & Laranja \\
\hline Teoria de Agência & $\operatorname{sim}$ & $\operatorname{sim}$ & $\operatorname{sim}$ & $\operatorname{sim}$ & $\operatorname{sim}$ & $\operatorname{sim}$ & $\operatorname{sim}$ \\
\hline Teoria da Estrutura de Capital & $\operatorname{sim}$ & - & - & - & $\operatorname{sim}$ & - & - \\
\hline Teoria da Sinalização & - & - & - & - & $\operatorname{sim}$ & - & - \\
\hline Teoria da Estrutura de Propriedade & $\operatorname{sim}$ & $\operatorname{sim}$ & $\operatorname{sim}$ & $\operatorname{sim}$ & $\operatorname{sim}$ & - & - \\
\hline Teoria dos Contratos & $\operatorname{sim}$ & - & - & - & - & - & - \\
\hline Stewardship Theory & - & - & & $\operatorname{sim}$ & - & - & - \\
\hline Stakeholder Theory & - & - & $\operatorname{sim}$ & - & $\operatorname{sim}$ & $\operatorname{sim}$ & - \\
\hline Resource Dependency Theory & - & - & - & $\operatorname{sim}$ & - & - & - \\
\hline $\begin{array}{l}\text { Teoria Comportamental dos } \\
\text { Conselhos de Administração }\end{array}$ & - & - & - & - & $\operatorname{sim}$ & - & - \\
\hline Behavioral Theory of the Firm & - & - & - & - & $\operatorname{sim}$ & - & - \\
\hline Institutional Theory & - & - & - & $\operatorname{sim}$ & $\operatorname{sim}$ & - & - \\
\hline Legitimacy Theory & - & - & - & $\operatorname{sim}$ & - & - & - \\
\hline Proprietary Costs Theory & - & - & - & $\operatorname{sim}$ & - & - & - \\
\hline Assimetria Informacional & $\operatorname{sim}$ & $\operatorname{sim}$ & $\operatorname{sim}$ & $\operatorname{sim}$ & - & - & - \\
\hline Efeito Entrincheiramento & $\operatorname{sim}$ & - & - & - & - & - & - \\
\hline
\end{tabular}

Fonte: elaborado pelos autores.

Por fim, a análise do acoplamento bibliográfico dos artigos publicados no período de 2014 a 2018 é apresentada na figura 6. Foram formados sete clusters, considerando um mínimo de 10 citações. A localização dos clusters deste período se apresenta mais definida do que nos períodos anteriores. Isto sugere maior homogeneidade dos trabalhos pesquisados, pois uma similaridade maior contribui positivamente para a formação de clusters mais bem definidos.

Figura 6 - Acoplamento bibliográfico, período 2014 a 2018.

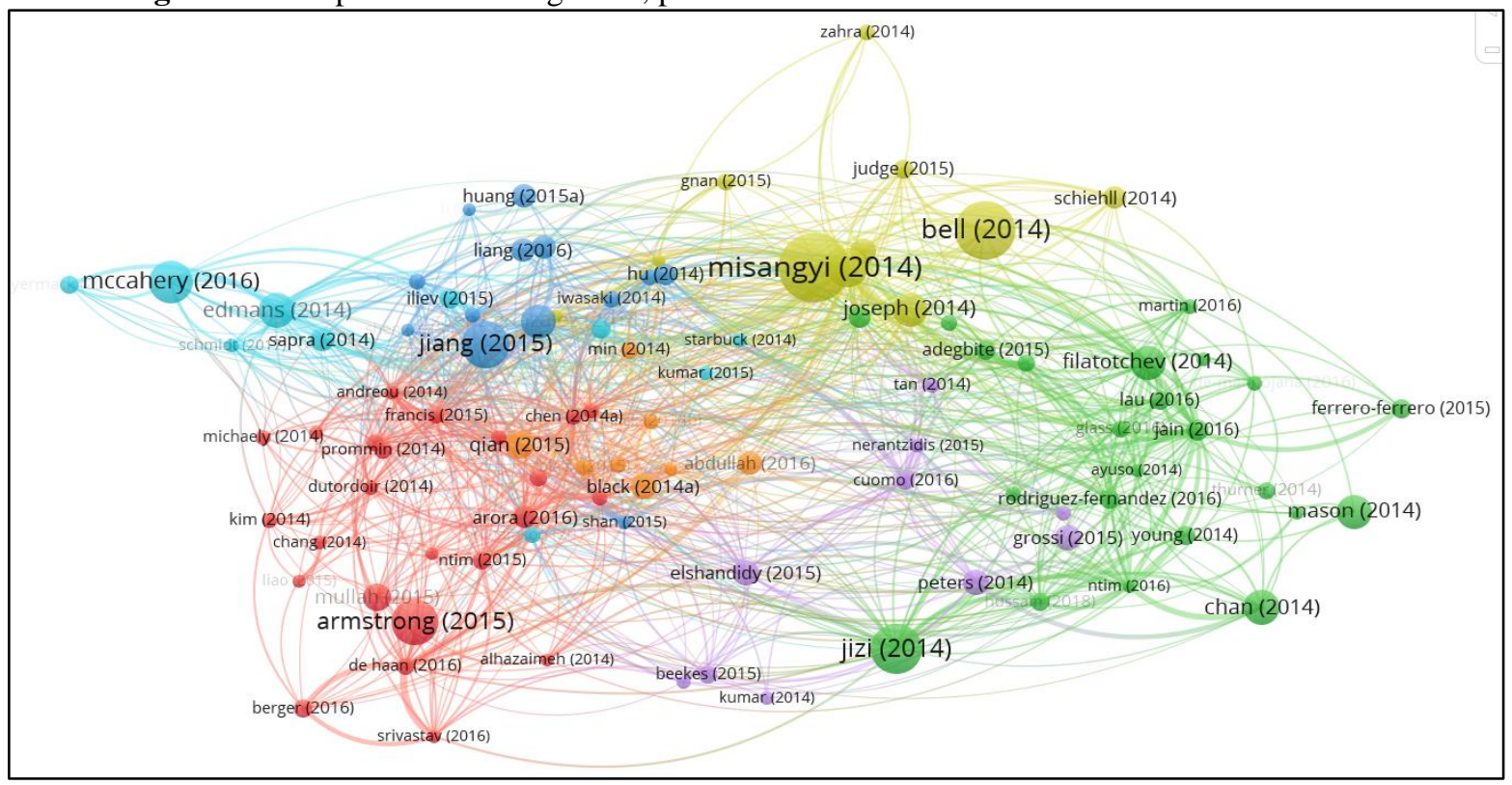

Fonte: elaborado pelos autores.

Este mapa apresenta uma particularidade: o tamanho dos círculos formados é, de certa forma, mais uniforme, podendo ser um indício de um período mais recente, onde as pesquisas ainda estão sendo incorporadas na literatura. $\mathrm{O}$ tamanho dos círculos observados nos outros períodos é mais heterogêneo, com círculos grandes, médios e pequenos. A análise dos artigos publicados neste período pode indicar as bases teóricas que estão sendo utilizadas nos estudos mais recentes sobre governança corporativa. O quadro 6 apresenta um resumo com as teorias e abordagens observadas por meio do acoplamento bibliográfico. 
Simões e Souza (2020)

Panorama da Literatura sobre a Governança Corporativa: uma Análise Bibliométrica das Bases Teóricas e Abordagens mais Utilizadas em Artigos

Quadro 6 - Acoplamento bibliográfico - período ano 2014 a 2018.

\begin{tabular}{|c|c|c|c|c|c|c|c|}
\hline & \multicolumn{7}{|c|}{ Clusters } \\
\hline & Vermelho & Verde & Roxo & Amarelo & Azul & Azul Claro & Laranja \\
\hline Teoria de Agência & $\operatorname{sim}$ & $\operatorname{sim}$ & $\operatorname{sim}$ & $\operatorname{sim}$ & $\operatorname{sim}$ & $\operatorname{sim}$ & $\operatorname{sim}$ \\
\hline Twin Agency Theory & - & - & - & - & $\operatorname{sim}$ & - & - \\
\hline Teoria da Estrutura de Capital & $\operatorname{sim}$ & - & - & - & - & $\operatorname{sim}$ & - \\
\hline Modern Portfolio Theory & - & - & - & - & - & $\operatorname{sim}$ & - \\
\hline Teoria da Sinalização & - & - & - & - & - & - & - \\
\hline Teoria da Estrutura de Propriedade & $\operatorname{sim}$ & - & $\operatorname{sim}$ & $\operatorname{sim}$ & $\operatorname{sim}$ & - & $\operatorname{sim}$ \\
\hline Teoria dos Contratos & - & - & - & - & - & - & - \\
\hline Stewardship Theory & $\operatorname{sim}$ & - & - & $\operatorname{sim}$ & $\operatorname{sim}$ & - & - \\
\hline Stakeholder Theory & & $\operatorname{sim}$ & $\operatorname{sim}$ & - & - & - & - \\
\hline Resource Dependency Theory & $\operatorname{sim}$ & $\operatorname{sim}$ & $\operatorname{sim}$ & $\operatorname{sim}$ & - & - & $\operatorname{sim}$ \\
\hline Knowledge-Based View & - & - & - & $\operatorname{sim}$ & - & - & - \\
\hline $\begin{array}{l}\text { Complementarity and Substitution } \\
\text { Perspectives }\end{array}$ & - & - & - & $\operatorname{sim}$ & - & - & - \\
\hline Innovation Theory & - & - & - & $\operatorname{sim}$ & - & - & - \\
\hline Efficiency Theory & - & - & $\operatorname{sim}$ & - & - & - & - \\
\hline $\begin{array}{l}\text { Teoria Comportamental dos } \\
\text { Conselhos de Administração }\end{array}$ & - & - & - & - & - & - & - \\
\hline Behavioral Theory of the Firm & - & - & - & $\operatorname{sim}$ & - & - & - \\
\hline Voice Theory & - & - & - & - & - & $\operatorname{sim}$ & - \\
\hline Institutional Theory & - & $\operatorname{sim}$ & $\operatorname{sim}$ & $\operatorname{sim}$ & - & - & - \\
\hline Neoinstitutional Theory & - & & $\operatorname{sim}$ & - & - & - & - \\
\hline Legitimacy Theory & - & $\operatorname{sim}$ & $\operatorname{sim}$ & - & - & - & - \\
\hline Proprietary Costs Theory & - & - & - & - & - & - & - \\
\hline Assimetria Informacional & $\operatorname{sim}$ & $\operatorname{sim}$ & $\operatorname{sim}$ & - & $\operatorname{sim}$ & - & - \\
\hline Efeito Entrincheiramento & - & - & - & - & $\operatorname{sim}$ & $\operatorname{sim}$ & - \\
\hline
\end{tabular}

Fonte: elaborado pelos autores.

Nos três períodos analisados estão presentes as pesquisas contábeis, pesquisas sobre a Responsabilidade Social Corporativa, pesquisas sobre a performance das empresas, pesquisas cross-country - com a China sendo o centro das atenções - e as pesquisas sobre mecanismos de governança, como o conselho de administração, CEOs, remuneração da alta administração, direitos dos acionistas, estrutura de propriedade, além de outros mecanismos de controle interno e externo. Não foram encontradas evidências que pudessem sugerir que as pesquisas sobre governança corporativa estejam passando por mudanças substanciais em relação às temáticas pesquisadas. Foi observado, a cada período, um aumento das abordagens e teorias de base utilizadas nos estudos sobre a governança corporativa. Isto pode sugerir que os pesquisadores realizam estudos com as abordagens tradicionais, mas também utilizam novas abordagens na tentativa de encontrar soluções para os problemas corporativos que se apresentam.

\subsection{SÍNTESE DAS ABORDAGENS E TEORIAS OBSERVADAS}

$\mathrm{Na}$ figura 7 são relacionadas as abordagens e teorias observadas por meio de mapeamento bibliométrico. Nesta figura, os retângulos representam as abordagens e teorias observadas nas pesquisas, os círculos representam a área de origem de determinada abordagem ou teoria, como por exemplo, as abordagens psicológicas e sociológicas que, conforme Davis, Schoorman e Donaldson (1997), deram origem a Stewardship Theory, e o losângulo, a área onde determinada abordagem foi mais citada, como por exemplo, a assimetria informacional e o efeito entrincheiramento, que foram mais observados nas pesquisas de Contabilidade.

Figura 7 - Abordagens e Teorias de base dos estudos de governança corporativa. 


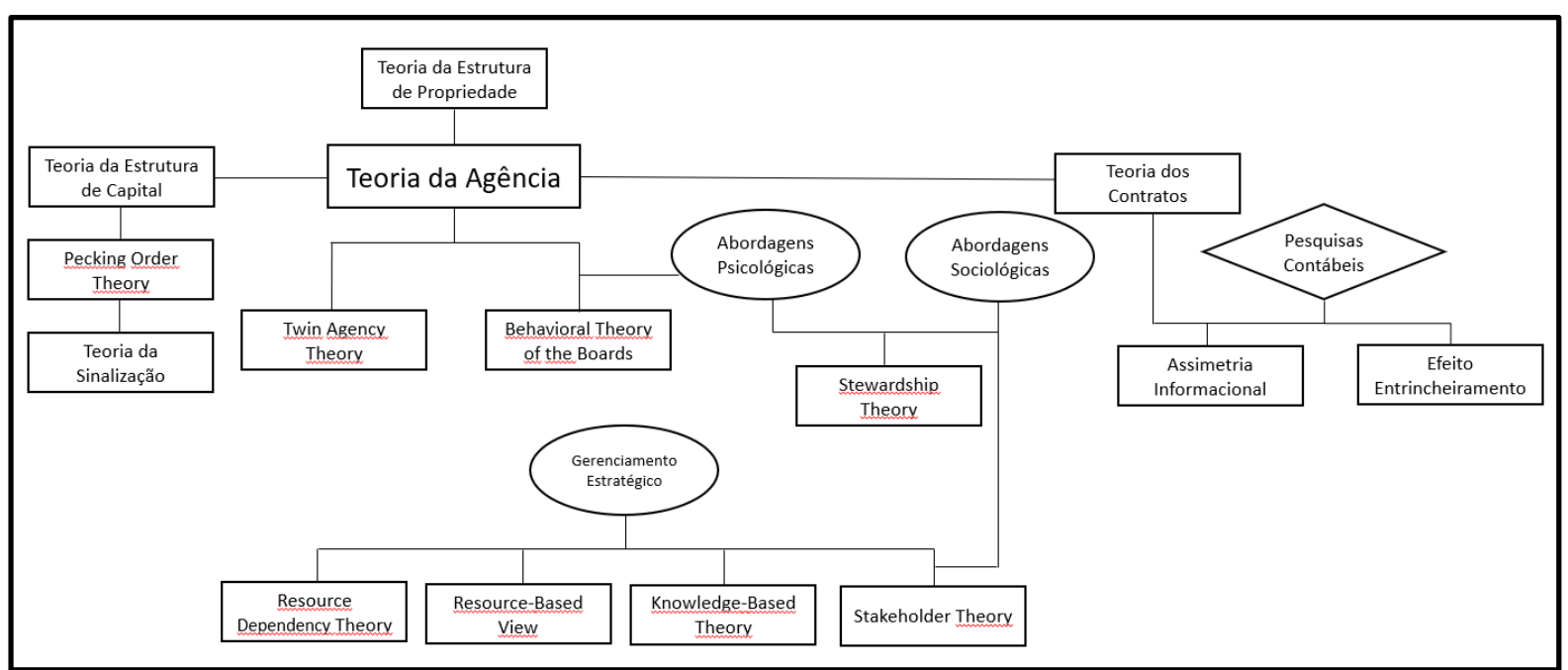

Fonte: elaborado pelos autores.

\section{CONSIDERAÇÕES FINAIS}

Nesta pesquisa foram investigadas as bases teóricas dos estudos sobre a governança corporativa através da análise de artigos obtidos junto à base de dados Web of Science, utilizando o software VOSviewer, por meio de mapeamento bibliométrico. Foram realizadas as análises de citações, de cocitações e o acoplamento bibliográfico em uma amostra contendo 2.965 artigos, divididos entre os anos de (i) 2000 a 2007, (ii) 2008 a 2013 e (iii) 2014 a 2018.

Com relação à quantidade de pesquisas realizadas em governança corporativa foi observado um aumento de 51,22\% de artigos publicados no segundo período e $14,38 \%$ no terceiro período. A leitura de pelo menos $15 \%$ dos artigos dos clusters de cada período mostra que eles abordaram o tema governança corporativa durante o período iniciado a partir dos eventos de estresse financeiro relatados. Isso pode sugerir que a Grande Crise Financeira de 2007-2008 levou os pesquisadores a desenvolver mais pesquisas abordando a temática da governança corporativa, em virtude dos impactos causados na economia americana e consequentemente, em suas corporações. Foi observado um aumento das pesquisas nos anos de 2009, que pode ter sido um reflexo dessa grande crise, assim como nos anos de 2015 e 2016, sugerindo um aumento das pesquisas em função do início do fim do QE, no qual as empresas teriam que se adaptar ao cenário de redução de liquidez nos mercados.

Por meio da análise de citações não foram observadas evidências de mudanças nas bases teóricas utilizadas nas pesquisas sobre governança corporativa uma vez que, em média, 82,37\% das citações se referem às mesmas bases teóricas utilizadas nos três períodos analisados. Isso pode ser um indício de que as bases teóricas utilizadas nestas pesquisas se originam de artigos seminais "consagrados", com a predominância da Teoria da Agência, estando de acordo com Davis, Schoorman e Donaldson (1997).

$\mathrm{Na}$ análise de cocitação de referências, as evidências encontradas por meio da análise dos clusters sugerem a predominância da Teoria da Agência como teoria de base nos estudos sobre a governança corporativa. Foi observada a presença de diferentes abordagens, na maioria das vezes, complementares à Teoria da Agência, que poderia ser um indício de uma movimentação no campo, auxiliando os agentes do mercado a enfrentar os cenários adversos. Todavia, ressalta-se que o cluster verde - identificado como Teoria da Agência e a Separação da Propriedade e Controle - engloba pesquisas até o início da década de 2000, podendo ser um indício de pesquisas realizadas para o estudo da governança corporativa no primeiro período analisado (2000 a 2007), em função do estouro da bolha das empresas pontocom e das fraudes contábeis nas empresas americanas. Da mesma forma, o cluster azul - Pesquisa Contábil - que 
engloba publicações até a primeira metade da década de 2000, é condizente com o desenvolvimento de pesquisas contábeis considerando a governança corporativa no primeiro período devido às fraudes contábeis.

Por último, as evidências encontradas por meio do acoplamento bibliográfico indicam que a Teoria de Agência é o paradigma dominante nas pesquisas sobre governança corporativa por ter sido observado em todos os três períodos analisados, seguida da Teoria da Estrutura de Propriedade. Destaca-se que no primeiro período (2000 a 2007) também foi observada a presença de estudos com bases teóricas com propostas concorrentes à Teoria da Agência, como a Stakeholder Theory e Stweardship Theory. Isso poderia ser um indício de estudos com enfoque diferentes à figura do gestor, daquele observado pela Teoria da Agência no que se refere aos conflitos entre principal e agente. Da mesma forma, no terceiro período (2014 a 2018), chama a atenção a presença da Resource Dependency Theory, no período que marcou o início do fim do Quantitative Easing.

Entretanto, foram observadas mudanças dentro das áreas, na análise do acoplamento bibliográfico. Por exemplo, em pesquisas Cross-Crountry, no primeiro período, foi observado que as pesquisas estavam voltadas à China e Rússia. No segundo período não foi observado a presença de um cluster de pesquisas Cross-Country. Por sua vez, no terceiro período, as pesquisas Cross-Coutry estavam voltadas para a China e mercados emergentes, sugerindo o impacto que os mercados emergentes sofreram com o fim da política monetária não convencional americana.

Portanto, é possível responder ao problema de pesquisa sobre quais as bases teóricas das pesquisas em governança corporativa considerando os eventos ocorridos, na medida em que as evidências sugerem a predominância da Teoria da Agência nos períodos analisados, corroborando os achados de Davis, Schoorman e Donaldson (1997). Entretanto, a Teoria da Estrutura de Propriedade foi observada de forma acentuada, quase sempre associada à Teoria da Agência. Foi observado também a presença da Stakeholder Theory, Stweardship Theory e Resource Dependency Theory que poderiam estar associadas aos eventos mencionados ocorridos nos Estados Unidos.

Foram analisados manualmente em torno de $15 \%$ dos artigos que compunham cada cluster, para nomeá-los. Apesar da análise imparcial, pode ter ocorrido um viés na interpretação dos artigos, configurando-se como uma limitação desta pesquisa. Para uma futura pesquisa, sugere-se que sejam investigadas as práticas de governança corporativa associadas às abordagens e teorias observadas nestas pesquisas, como forma de evitar novos escândalos financeiros e fraudes.

\section{REFERÊNCIAS}

ADAMS, R. B.; HERMALIN, B. E.; WEISBACH, M. S. The role of boards of directors in corporate governance: A conceptual framework and survey. Journal of Economic Literature, v. 48, n. 1, p. 58-107, 2010.

AGUILERA, R. V.; JACKSON, G. The cross-national diversity of corporate governance: Dimensions and determinants. Academy of management Review, v. 28, n. 3, p. 447-465, 2003.

AKERLOF, G. A. The market for "lemons": Quality uncertainty and the market mechanism. In: Uncertainty in economics. Academic Press, p. 235-251, 1978.

AYUSO, S.; RODRIGUEZ, M. A.; GARCIA-CASTRO, R.; ARIÑO, M. A. Maximizing stakeholders' interests: An empirical analysis of the stakeholder approach to corporate governance. Business \& Society, v. 53, n. 3, p. 414-439, 2014. 
BANK FOR INTERNATIONAL SETTLEMENTS (BIS). BIS 87th Annual Report. 2017. Disponível em: https://www.bis.org/publ/arpdf/ar2017e4.pdf. Acesso em: 09 set.2019.

BEBCHUK, L.; COHEN, A.; FERRELL, A. What matters in corporate governance?. The Review of Financial Studies, v. 22, n. 2, p. 783-827, 2008.

BELL, R. G.; FILATOTCHEV, I.; AGUILERA, R. V. Corporate governance and investors' perceptions of foreign IPO value: An institutional perspective. Academy of Management Journal, v. 57, n. 1, p. 301-320, 2014.

BERLE, A.; MEANS, G. The modern corporation and private property. New York: Macmillan, 1932.

BREALEY, R.; LELAND, H. E.; PYLE, D. H. Informational asymmetries, financial structure, and financial intermediation. The Journal of Finance, v. 32, n. 2, p. 371-387, 1977.

BURTON, B.; KUMAR, S.; PANDEY, N. Twenty-five years of The European Journal of Finance (EJF): a retrospective analysis. The European Journal of Finance, p. 1-25, 2020.

CASSELL, Catherine; CUNLIFFE, Ann L.; GRANDY, Gina (Ed.). The SAGE handbook of qualitative business and management research methods. Sage, 2017.

CHUNG, K. H.; WRIGHT, P.; KEDIA, B. Corporate governance and market valuation of capital and R\&D investments. Review of Financial Economics, v. 12, n. 2, p. 161-172, 2003.

DAVIS, J. H.; SCHOORMAN, F. D.; DONALDSON, L. Toward a stewardship theory of management. Academy of Management review, v. 22, n. 1, p. 20-47, 1997.

DE OLIVEIRA, Otávio José et al. Bibliometric method for mapping the state-of-the-art and identifying research gaps and trends in literature: an essential instrument to support the development of scientific projects. In: Scientometrics Recent Advances. IntechOpen, 2019.

DE VIJLDER, W. The normalization of US monetary policy: risks and challenges.

Conjoncture, v. 2, n. 1, p. 3-16. 2016. Disponível em: http://economic-

research.bnpparibas.com/Views/DisplayPublication.aspx?type=document\&IdPdf=27573.

Acesso em: 09 set. 2019.

DEANGELO, H.; MASULIS, R. W. Optimal capital structure under corporate and personal taxation. Journal of Financial Economics, v. 8, n. 1, p. 3-29, 1980.

DURAND, D. Costs of debt and equity funds for business: trends and problems of measurement. In: Conference on research in business finance. NBER, p. 215-262, 1952.

FAMA, E. F.; JENSEN, M. C. Separation of ownership and control. The journal of law and Economics, v. 26, n. 2, p. 301-325, 1983.

FREEMAN, R. E.; MCVEA, J. A stakeholder approach to strategic management. The Blackwell handbook of strategic management, p. 189-207, 2001.

GARCÍA-MACHADO, J. J. The latest streams in finance research: An updated bibliometric mapping based on co-occurrence data. In: Forum Scientiae Oeconomia. Wydawnictwo Naukowe Akademii WSB p. 7-25, 2018.

GOMPERS, P.; ISHII, J.; METRICK, A. Corporate governance and equity prices. The quarterly journal of economics, v. 118, n. 1, p. 107-156, 2003.

HART, O. Corporate governance: some theory and implications. The economic journal, v. 105, n. 430, p. 678-689, 1995. 
INSTITUTO BRASILEIRO DE GOVENANÇA CORPORATIVA [IBCG]. Origens da governança corporativa. São Paulo. 2018. Disponível em:

http://www.ibgc.org.br/governanca/origens-da-governanca. Acesso em: 27 ago. 2018.

IUDÍCIBUS, S.; LOPES, A. B. Teoria avançada da contabilidade. 2004.

JENSEN, M. C. The modern industrial revolution, exit, and the failure of internal control systems. the Journal of Finance, v. 48, n. 3, p. 831-880, 1993.

JENSEN, M. C.; MECKLING, W. H. Theory of the firm: Managerial behavior, agency costs and ownership structure. Journal of financial economics, v. 3, n. 4, p. 305-360, 1976.

JIZI, M. I.; SALAMA, A.; DIXON, R.; STRATLING, R. Corporate governance and corporate social responsibility disclosure: Evidence from the US banking sector. Journal of business ethics, v. 125, n. 4, p. 601-615, 2014.

KALEMLI-ÖZCAN, Șebnem. US monetary policy and international risk spillovers. National Bureau of Economic Research, 2019.

KESSLER, M. M. Bibliographic coupling between scientific papers. American documentation, v. 14, n. 1, p. 10-25, 1963.

LA PORTA, R.; LOPEZ-DE-SILANES, F.; SHLEIFER, A.; VISHNY, R.W. Law and finance. Journal of political economy, v. 106, n. 6, p. 1113-1155, 1998.

LA PORTA, R.; LOPEZ-DE-SILANES, F.; SHLEIFER, A.; VISHNY, R.W. Agency problems and dividend policies around the world. The journal of finance, v. 55, n. 1, p. 1-33, 2000.

MARANHO, F. S.; DA FONSECA, M. W.; FREGA, J. R. Governança corporativa e desempenho das empresas diante da crise econômica global de 2008: uma análise de dados em painel. Revista de Administração da Universidade Federal de Santa Maria, v. 9, n. 2, p. 293-311, 2016.

MEYER, J. W.; ROWAN, B. Institutionalized organizations: Formal structure as myth and ceremony. American journal of sociology, v. 83, n. 2, p. 340-363, 1977.

MILLER, M. H.; ROCK, K. Dividend policy under asymmetric information. The Journal of finance, v. 40, n. 4, p. 1031-1051, 1985.

MISANGYI, V. F.; ACHARYA, A. G. Substitutes or complements? A configurational examination of corporate governance mechanisms. Academy of Management Journal, v. 57, n. 6, p. 1681-1705, 2014.

MODIGLIANI, F.; MILLER, M. H. The cost of capital, corporation finance and the theory of investment. The American, v. 1, p. 3, 1958.

MORCK, R.; SHLEIFER, A.; VISHNY, R. W. Management ownership and market valuation: An empirical analysis. Journal of Financial Economics, v. 20, p. 293-315, 1988.

MORCK, R.; STEIER, L. The global history of corporate governance: An introduction. In: A history of corporate governance around the world: Family business groups to professional managers. University of Chicago Press, p. 1-64, 2005.

MYERS, S. C.; MAJLUF, N. S. Corporate financing and investment decisions when firms have information that investors do not have. Journal of Financial Economics, v. 13, n. 2, p. 187-221, 1984. 
Panorama da Literatura sobre a Governança Corporativa: uma Análise Bibliométrica das Bases Teóricas e Abordagens mais Utilizadas em Artigos

PALLUDETO, A. W. A.; FELIPINI, A. R. Panorama da literatura sobre a financeirização (1992-2017): uma abordagem bibliométrica. Economia e Sociedade, v. 28, n. 2, p. 313-337, 2019.

ROSS, S. A. The determination of financial structure: the incentive-signalling approach. The Bell Journal of Economics, p. 23-40, 1977.

ROSSONI, Luciano. Governança corporativa, legitimidade e desempenho das organizações listadas na Bovespa. Curitiba: Tese de Doutorado (Administração) Universidade Federal do Paraná, 2009.

SHLEIFER, A.; VISHNY, R. W. A survey of corporate governance. The Journal of Finance, v. 52, n. 2, p. 737-783, 1997.

SILVEIRA, A. Governança corporativa em empresas de controle familiar: Casos de destaque no Brasil. IBCG, São Paulo, 2006.

SINKOVICS, Rudolf R. et al. Enhancing the foundations for theorising through bibliometric mapping. International Marketing Review, 2016.

STULZ, R. M. The limits of financial globalization. The Journal of Finance, v. 60, n. 4, p. 1595-1638, 2005.

VAN ECK, N.; WALTMAN, L. Software survey: VOSviewer, a computer program for bibliometric mapping. Scientometrics, v. 84, n. 2, p. 523-538, 2010.

VAN ECK, N. J.; WALTMAN, L. Visualizing bibliometric networks. In: Measuring scholarly impact. Springer, Cham, 2014. p. 285-320.

YOUNG, M. N. et al. Corporate governance in emerging economies: A review of the principal-principal perspective. Journal of Management Studies, v. 45, n. 1, p. 196-220, 2008. 